\title{
The grand challenge to operationalize landscape sustainability and the design-in-science paradigm
}

\author{
Laura R. Musacchio
}

Received: 27 October 2010/Accepted: 18 November 2010/Published online: 3 December 2010

(C) Springer Science+Business Media B.V. 2010

\section{Introduction}

As a concept, landscape sustainability is becoming an increasingly important topic in landscape ecology; yet it remains not clearly defined in theory, methodology, or application (Musacchio 2009a, b). For example, the synthesis article by Wu and Hobbs (2002) identified landscape sustainability as one of ten key topics for landscape ecology in the 21 st century. Sustainability science emerged at about the same time as their article and seemed to be highly compatible with landscape sustainability, but sustainability science's potential has never been fully realized in landscape ecology because it too remains undefined and abstract. Yet, the debate about the role of the sustainability paradigm and sustainability science in this discipline has intensified in the past several years with the publication of numerous articles (Potschin and Haines-Young 2006; Nassauer and Opdam 2008; Wu 2008, 2010; Musacchio 2009a, b; Termorshuizen and Opdam 2009; Wiens 2009; Pearson and McAlpine 2010.

One of the grand challenges of landscape ecology in the coming decades will be how to leverage sustainability science and sustainable design to improve

L. R. Musacchio $(\square)$

Landscape Architecture, Conservation Biology, Urban and Regional Planning, and Water Resources Science Programs, University of Minnesota, 89 Church St. SE, Minneapolis, MN 55455, USA

e-mail: musac003@umn.edu

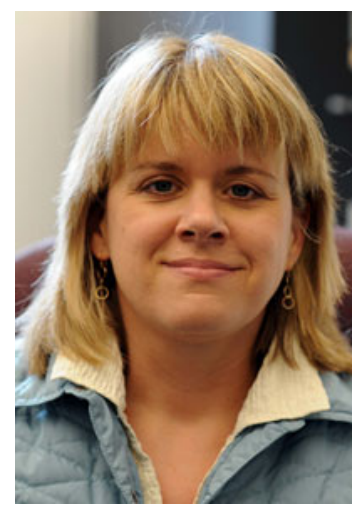

knowledge and innovation about ecology and culture of landscapes, the basis of landscape sustainability. The importance of the relationship between ecology and culture to the future of landscape ecology cannot be overstated, and this editorial is inspired by Wu's recent editorial (2010) about this issue. The central issue is that a more unified and comprehensive knowledge base is needed for better science and practice. In addition, its theory and practice needs to be more pluralistic and ecumenical approaches to reach its transdisciplinary goals (Wu 2006, 2010).

The special issue The Ecology and Culture of Landscape Sustainability: Emerging Knowledge and Innovation in Landscape Research and Practice (see Musacchio 2009a, b) begins the process of conceptually framing the scope and boundaries of key concepts, mental maps, and research priorities with the six Es of landscape sustainability (Fig. 1). Figure 2 is the next 


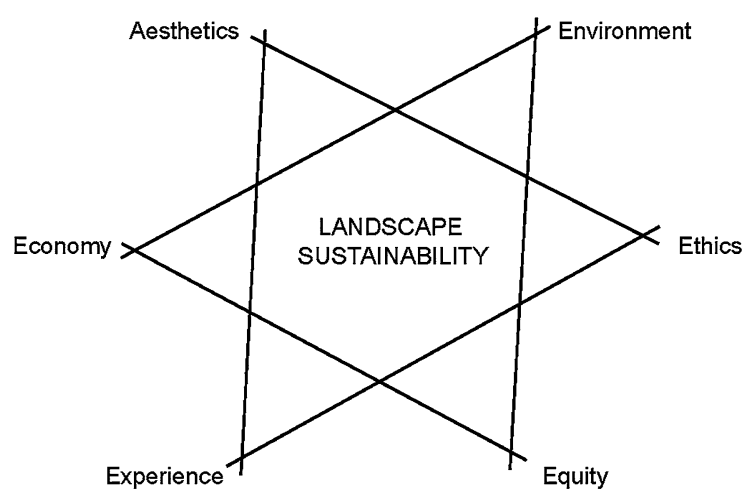

Fig. 1 The six Es of landscape sustainability: environment, economics, equity, aesthetics, experience, and ethics. See Musacchio (Fig. 3, 2009b) for more information. (C) Laura R. Musacchio; used with permission)

step to operationalize landscape sustainability and conceptually identifies the disciplines that will be catalysts for creating the research and practice agenda for the ecology and culture of landscape sustainability. The first triangle includes several key disciplines in science-based disciplines like landscape ecology, sustainability science, and design sciences (e.g., landscape planning). These disciplines provide important synergy around the key concepts like landscape structure, function, and change, but their knowledge and contributions are not enough to operationalize landscape sustainability. For this reason, a second triangle is added representing practice-based disciplines, which include landscape architecture, sustainable development, and sustainable design. The overlap between these two triangles represent the shared mental space among the disciplines that will provide the intellectual, emotional, and motivational synergy to operationalize landscape sustainability.

\section{Key questions for operationalizing landscape sustainability}

With this introduction in mind, these five key questions help to capture some of the most basic issues for addressing the grand challenge of operationalizing landscape sustainability and the design-inscience paradigm:

1. How can sustainability science and sustainable design be better integrated into the theory, methodology, and application of landscape ecology?

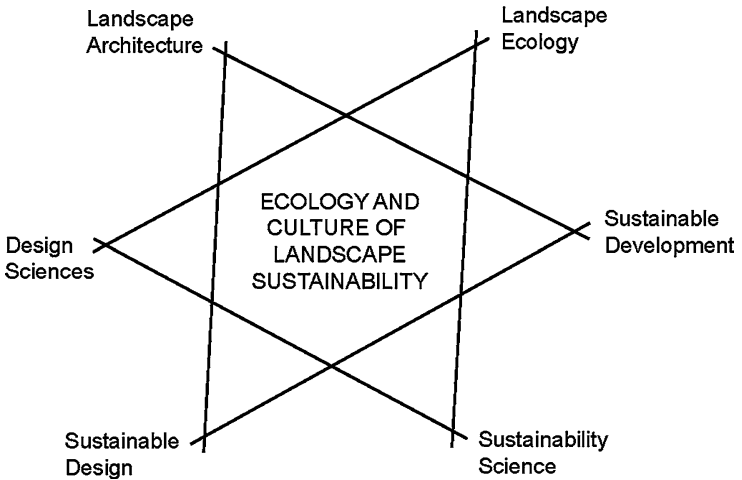

Fig. 2 Disciplines that will be catalysts for creating the research and practice agenda for the ecology and culture of landscape sustainability. The overlap between these two triangles represents the shared mental space among these disciplines that will provide the intellectual, emotional, and motivational synergy to operationalize landscape sustainability. (C) Laura R. Musacchio; used with permission)

2. What are the scope and boundaries of landscape sustainability in relation to the theory, methodology, and application of landscape ecology?

3. What key issues, concepts, and priorities are most important to landscape sustainability in relation to holistic landscape ecology and landscape ecology in action?

4. How is landscape sustainability influenced by human(culture)-nature interactions across scales?

5. How can the design sciences help to bridge epistemological and methodological gaps among sustainability science, sustainable design, landscape architecture, sustainable development, and landscape ecology?

These questions are a beginning point for operationalizing additional topics, principles, concepts, issues, and research questions about landscape sustainability; and they will need to address complex place-based problems and the struggle to manage the commons across scales (see Musacchio 2009b). Above all, the questions will need to address what $\mathrm{Wu}$ (2006) calls the gradual shift in the dominant research mode of science from field research at plotscale to problem solving at the place-scale, which involves increasing subjectivity and uncertainty (Musacchio 2009b). This shift favors questions embracing knowledge and approaches not only in sustainability science and landscape ecology but also in the design sciences. To fully address these 
questions, researchers and practitioners must consider how the emergence of the design-in-science paradigm might reshape the existing contours of knowledge, epistemologies, methodologies, and approaches.

\section{The paradigm shift: the emergence of design-in-science}

In the past decade, the emergence of the design-inscience paradigm represents a major intellectual convergence between the theories and practices of the ecological and design disciplines. For example, Nassauer and Opdam (2008) in their article Design in Science bring clarity to how it can extend the landscape ecology paradigm by redefining design as the essential connection between science and practice, which they call pattern:process:design paradigm. Other examples along this line of thinking include Benyus (2002), Musacchio and Wu (2004), Felson and Pickett (2005), Wu (2008), Musacchio (2009a, b), and Opdam (2010). Moreover, restoration ecology also has been concerned about the role of design in the rehabilitation and restoration of landscapes, ecosystems, and habitats (e.g., Gobster and Hull 2000; Higgs 2003; Palmer et al. 2004, Lindenmayer and Hobbs 2007; Martínez and López-Barrera 2008; Jones and Monaco 2009). In this editorial, I elevate design-in-science to a paradigm for several reasons: (1) it complements what Nassauer and Opdam (2008) recently proposed with the pattern:process:design paradigm; (2) it has potential to inform not only landscape process and pattern relationships but also other integrative concepts in landscape ecology like scale, spatial heterogeneity, and landscape sustainability; (3) it addresses issues being raised across a broad spectrum of disciplines who are interested integrating transdisciplinary science and practice, sustainability science, sustainable design, and so on; and (4) it complements the conceptual framework for landscape sustainability in my recent article (Musacchio 2009b).

A major dilemma for better integration between sustainability science and landscape ecology is that science (e.g., ecological, physical, and social sciences) has not fully recognized the value of the design-in-science paradigm. The current interdisciplinary paradigm of biophysical science-social science model, which was put into place at the National

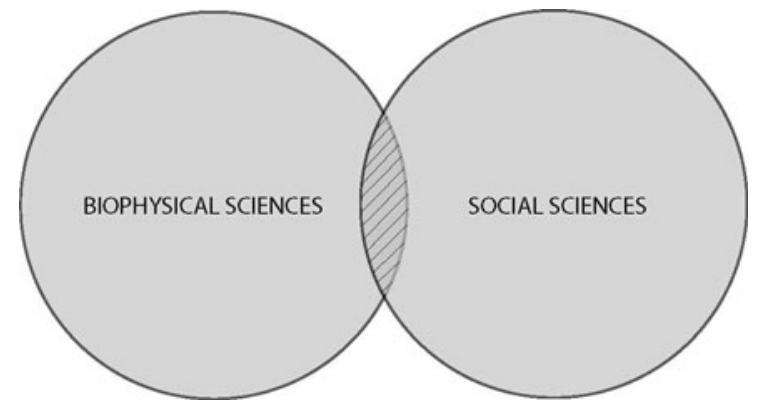

Fig. 3 The traditional science paradigm conceives interdisciplinary collaboration as a coupled model that brings together only the biophysical sciences and social sciences (C) Laura R. Musacchio; used with permission)

Science Foundation (United States) more than a decade ago, places much less emphasis on the contributions of landscape research and practice for enhancing scientific knowledge and innovation. Science is conceived as a coupled system that brings together the traditional scientific disciplines-the biophysical sciences with the social sciences (Fig. 3). Practice in this model is most likely conceived as environmental education, public outreach, or citizen participation. This epistemological conception of interdisciplinary collaboration limits the potential innovation with science's natural partner in knowledge — design — which has the intuitive and instinctive sensibility for creative application of science and art and can help engage the public to understand human-nature interactions in places, which are at the scale of human experience.

At the time of its conception, the biophysicalsocial science model served a very important purpose because of the lack of cross-disciplinary research among these disciplines; but after more than a decade of its use, its limitations have become more apparent as more integrative concepts have been emphasized like landscape sustainability. For example, culture is buried in many of the discussions and articles about sustainability and coupled systems; and a hidden assumption exists that culture happens somewhere in the background of social-ecological systems. When addressing integrative concepts like landscape sustainability, culture cannot be ignored because cultural factors along with social factors are critical for shaping acceptance of adaptive management plans, land conservation plans, best management practices, landscape performance systems, and so on. 
A second limitation of the biophysical-social science model is how individuals are classified as either ecological, physical, or social scientists; labels that do not necessarily fit well with individuals involved in landscape research and practice. This limitation will become even more apparent as scientists try to adapt and apply their knowledge with collaborators, like landscape ecologists who are trained as landscape planners. This lack of flexibility in the biophysical-social social science model is why numerous scientists in landscape ecology and restoration ecology keep emphasizing why design is the missing ingredient in today's scientific paradigms. This dramatic shift in thinking represents the emergence of the design-in-science paradigm; and this paradigm will eventually spread to all of the sciences in the coming decades. The design-in-science paradigm will extend the biophysical-social science model toward new epistemologies, methods, and approaches for collaboration that will help to operationalize landscape sustainability. For example, Fig. 4 illustrates a conceptual framework for transdisciplinary collaboration that builds off of a conceptual framework for translational landscape research and practice that I presented in another article (Musacchio, Fig. 4, 2009b). This conceptual framework in this editorial is more robust and represents a more advanced level of how I am thinking about how to operationalize landscape sustainability. The central theme is that people need to think more systemically across scales to experience the interconnections in living systems because their perceptual limitations tend to focus most on the scale of human experience. This conceptual framework begins to briefly flesh out these relationships more clearly and precisely.

Figure 4 represents how the design-in-science paradigm (first frame) will provide the conceptual structure and organization for unifying the three inner frames: to operationalize landscape sustainability (second frame); to reconfigure the collaborative relationships among science and practice disciplines (third frame); and to discover new useful knowledge about four themes of landscape sustainability and people's contact with nature (fourth frame). Landscape sustainability (second frame) integrates the science-in-design paradigm in the first frame and the disciplines in the third frame-landscape research and practice, social sciences, biophysical sciences,

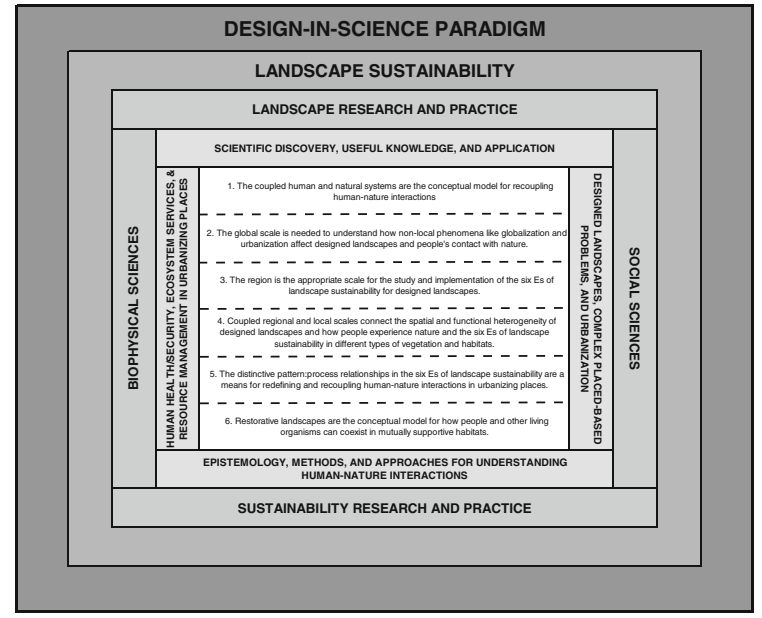

Fig. 4 illustrates a conceptual framework for transdisciplinary collaboration that builds off of a conceptual framework that I presented in another article (Musacchio, Fig. 4, 2009b). This figure represents how the design-in-science paradigm (first frame) will provide the conceptual structure and organization for unifying the three inner frames and key characteristics and principles: to operationalize landscape sustainability (second frame); to reconfigure the collaborative relationships among science and practice disciplines (third frame); to discover new useful knowledge about four themes of landscape sustainability and people's contact with nature (fourth frame); and to connect the key characteristics and principles in the framework's core across scales. (ㄷ Laura R. Musacchio; used with permission)

and sustainable design and practice. The disciplines in the third frame will be involved with operationalizing landscape sustainability in the second frame and connecting it to the four themes in the fourth frame. This last frame provides the conceptual structure and organization for the key characteristics and principles. The core of the conceptual framework includes key characteristics and principles that provide greater specificity to the four layers and relate knowledge to landscape sustainability and the designin-science paradigm. For a more thorough explanation of these key characteristics and principles, please see Musacchio (2009b).

\section{Parting words}

Landscape ecology is one of the few disciplines within ecology to openly address the cultural dimension of landscapes and sustainability because of the influences of geography, landscape planning, and landscape architecture. The complexity of this topic 
means that this editorial may actually raise more questions than it can answer due to space constraints. Yet, much work remains to fully operationalize how ecology and culture mix to create sustainable landscapes. More landscape ecologists are wondering how sustainability science can help the discipline reach its visionary potential because of the debate about the role of design-in-science. The next step is to create a blueprint to help landscape ecology to catalyze and actualize its visionary potential with the help of design-in-science paradigm.

Acknowledgments I want to thank Jianguo $\mathrm{Wu}$, David Hulse, and Forster Ndubisi for their insightful feedback while I was developing this editorial.

\section{References}

Benyus J (2002) Biomimicry: innovation inspired by design. Harper Perennial, New York

Felson AJ, Pickett STA (2005) Designed experiments: new approaches to studying urban ecosystems. Front Ecol Environ 3:549-556

Gobster P, Hull RB (2000) Restoring nature: perspectives from the social sciences and humanities. Island Press, Washington DC

Higgs E (2003) Nature by design: people, natural process, and ecological restoration. The MIT Press, Cambridge

Jones TA, Monaco TA (2009) A role for assisted evolution in designing native plant materials for domesticated landscapes. Front Ecol Environ 7:541-547

Lindenmayer D, Hobbs R (2007) Managing and designing landscapes for conservation: moving from perspectives to principles. Wiley-Blackwell, New York

Martínez ML, López-Barrera G (2008) Special issue: restoring and designing ecosystems for a crowded planet. Ecoscience $15: 1-5$

Musacchio L (2009a) The ecology and culture of landscape sustainability: emerging knowledge and innovation in landscape research and practice. Landscape Ecol 24:989-992

Musacchio L (2009b) The scientific basis of design for landscape sustainability: a conceptual framework for translational landscape research and practice of designed landscapes and the six Es of landscape sustainability. Landscape Ecol 24:993-1013

Musacchio L, Wu J (2004) Collaborative landscape-scale ecological research: emerging trends in urban and regional ecology. Urban Ecosyst 7:175-178

Nassauer JI, Opdam P (2008) Design in science: extending the landscape ecology paradigm. Landscape Ecol 23:633-644

Opdam P (2010) Learning science from practice. Landscape Ecol 25:821-823

Palmer M, Bernhardt E, Chornesky E, Collins S, Dobson A, Duke C, Gold B, Jacobson R, Kingsland S, Kranz R, Mappin M, Martinez ML, Micheli F, Morse J, Pace M, Pascual M, Palumbi S, Reichman OJ, Simons A, Townsend A, Turner M (2004) Ecology for a crowded planet. Science 304:1251-1252

Pearson D, McAlpine C (2010) Landscape ecology: an integrated science for sustainability in a changing world. Landscape Ecol 25:1151-1154

Potschin M, Haines-Young R (2006) "Rio + 10”, sustainability science and landscape ecology. Landsc Urban Plan 75:162-174

Termorshuizen J, Opdam P (2009) Landscape services as a bridge between landscape ecology and sustainable development. Landscape Ecol 24:1037-1052

Wiens J (2009) Landscape ecology as a foundation for sustainable conservation. Landscape Ecol 24:1053-1065

Wu J (2006) Landscape ecology, cross-disciplinarity, and sustainability science. Landscape Ecol 21:1-4

Wu J (2008) Making the case for landscape ecology: an effective approach for urban sustainability. Landsc J 27:41-50

Wu J (2010) Landscape of culture and culture of landscape: does landscape ecology need culture? Landscape Ecol 25:1147-1150

Wu J, Hobbs R (2002) Key issues and research priorities in landscape ecology: an idiosyncratic synthesis. Landscape Ecol 17:355-365 